\title{
The impact of herpes zoster and postherpetic neuralgia on health-related quality of life: a prospective study
}

\author{
Mélanie Drolet PhD, Marc Brisson PhD, Kenneth E. Schmader MD, Myron J. Levin MD, \\ Robert Johnson MD, Michael N. Oxman MD, David Patrick MD, Caty Blanchette MSc, \\ James A. Mansi PhD
}

Previously published at www.cmaj.ca

$\infty \infty$

See related commentary by Watson, page 1713

\section{ABSTRACT}

Background: Vaccination against herpes zoster is being considered in many countries. We conducted a multicentre prospective study to describe the impact of herpes zoster and postherpetic neuralgia on health-related quality of life.

Methods: From October 2005 to July 2006, 261 outpatients aged 50 years or older with herpes zoster were recruited from the clinical practices of 83 physicians within 14 days after rash onset. The Zoster Brief Pain Inventory was used to measure severity of pain and interference with activities of daily living because of pain. The EuroQol EQ-5D assessment tool was used to measure quality of life. These outcomes were assessed at recruitment and on days 7, 14, 21, $30,60,90,120,150$ and 180 following recruitment.

Results: Acute herpes zoster interfered in all health domains, especially sleep ( $64 \%$ of participants), enjoyment of life $(58 \%)$ and general activities $(53 \%)$. The median duration of pain was 32.5 days. The median duration of interference with activities of daily living because of pain varied between 27 and 30 days. Overall, $24 \%$ of the participants had postherpetic neuralgia (pain for more than 90 days after rash onset). Anxiety and depression, enjoyment of life, mood and sleep were most frequently affected during the postherpetic neuralgia period. The mean EQ-5D score was 0.59 at enrolment and remained at 0.67 at all follow-up points among participants who reported clinically significant pain.

Interpretation: These data support the need for preventive strategies and additional early intervention to reduce the burden of herpes zoster and postherpetic neuralgia. erpes zoster, which is characterized by dermatomal pain and vesicular rash, ${ }^{1,2}$ results from reactivation of the varicella-zoster virus. ${ }^{3,4}$ The average lifetime risk of herpes zoster in developed countries is estimated to be about $30 \% \%^{5-7}$ and increases with increasing life expectancy. The most common complication of herpes zoster, and one of the most challenging to treat, is postherpetic neuralgia, a painful condition often defined as pain persisting for more than 90 days after rash onset. ${ }^{8}$ According to this definition, postherpetic neuralgia is estimated to occur in $8 \%-27 \%$ of people with herpes zoster overall..$^{9-14}$ The risk of postherpetic neuralgia increases markedly with age. ${ }^{15}$

The Shingles Prevention Study, a randomized doubleblind placebo-controlled trial, showed that a live-attenuated varicella-zoster virus vaccine was safe and effective in preventing herpes zoster and postherpetic neuralgia among people 60 years of age and older. ${ }^{13}$ Given these promising results, policy-makers and clinicians are being asked to make recommendations regarding the use and funding of the herpes zoster vaccine. To do this, evidence on the burden of herpes zoster from the patient's perspective is required. The only data available on the impact of herpes zoster on health-related quality of life comes from two short-term studies ${ }^{16,17}$ Clinical reports and cross-sectional surveys ${ }^{18-20}$ have also suggested that postherpetic neuralgia can profoundly impair quality of life. However, no study followed a cohort of patients with newly diagnosed herpes zoster for a sufficient period to assess postherpetic neuralgia and describe the associated impact on quality of life.

We undertook a multicentre prospective study to describe the impact of herpes zoster and postherpetic neuralgia on health-related quality of life.

From the Unité de recherche en santé des populations, Centre hospitalier affilié universitaire de Québec (Drolet, Brisson, Blanchette), Québec, Que.; the Département de médecine sociale et préventive, Université Laval (Drolet, Brisson), Québec, Que.; the Center for the Study of Aging and Human Development, Division of Geriatrics, Department of Medicine, Duke University Medical Center, and the Geriatric Research, Education and Clinical Center, Durham VA Medical Center (Schmader), Durham, USA; the Department of Pediatrics and Medicine, University of Colorado, Denver, and the Health Sciences Center (Levin), Aurora, USA; the University of Bristol and Bristol Royal Infirmary (Johnson), Bristol, UK; the Department of Medicine and Pathology, University of California at San Diego and the San Diego VA Medical Center (Oxman), La Jolla, USA; and the Department of Medicine, University of British Columbia, and the BC Centre for Disease Control (Patrick), Vancouver, BC. James Mansi was an employee of Merck Frosst Canada Ltd. (Scientific Affairs) during protocol development, study execution, data analysis and manuscript submission; he is currently an employee of Novartis Pharmaceuticals Canada Inc. (Novartis Vaccines \& Diagnostics).

CMAJ 2010. DOI:10.1503/cmaj.091711 


\section{Methods}

\section{Recruitment}

Between October 2005 and July 2006, a total of 574 outpatients aged 50 years and older with a physician-confirmed diagnosis of herpes zoster were recruited at different times after rash onset. Of these patients, 266 were recruited within 14 days after rash onset and were considered to have incident herpes zoster. All of our analyses of the impact of herpes zoster and postherpetic neuralgia on health-related quality of life were restricted to these patients.

Recruitment took place during the course of clinical practice of 83 general practitioners or specialists across Canada. Although the diagnosis of herpes zoster is generally straightforward, it can sometimes be confused with herpes simplex. To increase the validity of diagnosis, all recruiting physicians participated in a training session on the differential diagnosis of herpes zoster offered by an expert in herpes zoster. Furthermore, physicians collected a sample of the lesion fluid or scab from the rash of their first three enrolled patients (corresponding to $41 \%$ of all patients recruited within 14 days after rash onset). The samples were analyzed by means of polymerase chain reaction testing for the presence of varicellazoster virus DNA, which was confirmed in 95\% (103/108) of specimens. The five patients whose herpes zoster could not be confirmed were excluded from the analysis. This left 261 participants in the study, $233(89.3 \%)$ of whom were recruited by general practitioners and $28(10.7 \%)$ by specialists.

The study protocol was approved by the Canadian SHIELD Ethics Review Board. All participants signed informed consent.

\section{Data collection}

At recruitment, the physician documented the patient's demographic characteristics, date of rash onset, dermatome affected, nature and number of lesions, treatments, other pain conditions, and immune status. The following criteria were used by physicians to define immunocompromised patients: oral corticosteroid treatment ( $\geq 20 \mathrm{mg} / \mathrm{d}$ or more of prednisone or equivalent); cancer or HIV/AIDS; and current or recent receipt of cytotoxic or immunosuppressive treatment for cancer or organ transplant.

The first questionnaire was completed by the patient at the physician's office during the recruitment visit. Follow-up questionnaires were completed at home on days $7,14,21,30$, $60,90,120,150$ and 180 following recruitment. The first questionnaire included detailed socio-demographic information. All 10 questionnaires included questions on the severity of pain related to herpes zoster or postherpetic neuralgia and quality of life.

\section{Outcome measures}

The outcome measures were herpes zoster pain and post herpetic neuralgia, interference with activities of daily living and health-related quality of life.

Pain and discomfort related to herpes zoster were measured by means of the Zoster Brief Pain Inventory, a modified version of the Brief Pain Inventory specific to herpes zoster that includes other discomfort (e.g., itch) in the area of the rash in addition to pain. ${ }^{8}$ This instrument measures the severity of current, least, worst and average pain and discomfort within the past 24 hours using an 11-point Likert scale $(0=$ no pain, $10=$ pain as bad as you can imagine). This instrument was used in the Shingles Prevention Study ${ }^{13}$ and has good reliability and validity. ${ }^{8}$ As suggested by Coplan and colleagues, ${ }^{8}$ who showed that herpes zoster pain scores of less than three reported more than 30 days after rash onset had minimal impact on activities of daily living, ${ }^{8}$ we considered pain to be clinically significant (a) if any pain score was recorded between rash onset and 30 days and (b) if pain scores of three or higher were recorded more than 30 days after rash onset. Postherpetic neuralgia was defined as pain that was assigned a worst pain score of three or higher by the patient and that began at or persisted for more than 90 days after rash onset. ${ }^{8}$

The Zoster Brief Pain Inventory also measures, on an 11point Likert scale $(0=$ does not interfere, $10=$ completely interferes), the interference of pain from herpes zoster with seven activities of daily living: general activity, mood, walking ability, work, relation with others, sleep and enjoyment of life. To allow for comparisons with findings from previous studies, ${ }^{17,21}$ we used a cut-off of five or higher to distinguish between participants who experienced substantial interference and those with no or little interference.

The EuroQol EQ-5D is a utility instrument widely used in cost-effectiveness analyses that can also be used as a generic measure of health-related quality-of-life..$^{22}$ It consists of five dimensions: mobility, self-care, usual activities, pain or discomfort, and anxiety or depression. Individuals are asked to indicate their level of problems in each dimension (no problem, some problems or severe problems). The combination of the answers to the five dimensions results in 243 possible health states. We used the English scoring system ${ }^{23}$ to translate the health states of our participants into utility scores ranging from 0 (worst health) to 1 (perfect health). Although the American and English scoring systems have been found to generate EQ$5 \mathrm{D}$ index scores with equivalent psychometric properties in the measurement of quality of life,,$^{24}$ we verified that our results were consistent when using the American scoring system. ${ }^{25}$

\section{Statistical analysis}

To describe the change in quality of life over time for the study cohort and to take advantage of the repeated measures of pain and quality-of-life outcomes, we used two different statistical models. For continuous variables (EQ-5D mean scores), we used piece-wise linear regression models to allow for different slopes of change over time. These models optimize the use of data by including all observations for one individual regardless of their number or timing. ${ }^{26}$ Previous work indicated that severity of pain from herpes zoster decreases substantially from rash onset to 30 days. The severity continues to decrease, at a slower rate, between 30 and 90 days and remains relatively stable thereafter. ${ }^{27-29}$ Because the quality of life of individuals with herpes zoster is highly correlated with the severity of pain, ${ }^{17}$ two knots were set in the curves of quality-of-life evolution at 30 and 90 days after rash onset. We also assessed the correlation between severity of pain and quality of life 
Table 1: Baseline characteristics of 261 patients aged 50 and older with herpes zoster who were recruited within 14 days after rash onset

\begin{tabular}{|c|c|}
\hline Characteristics & $\begin{array}{c}\text { No. }(\%) \\
\text { of patients* } \\
n=261\end{array}$ \\
\hline \multicolumn{2}{|l|}{ Patient } \\
\hline Age at rash onset, yr, mean (SD) & $65.4(10.8)$ \\
\hline Sex, male & $109(41.8)$ \\
\hline Employed & $85(32.8)$ \\
\hline \multicolumn{2}{|l|}{ Province } \\
\hline Quebec & $90(34.5)$ \\
\hline Ontario & $88(33.7)$ \\
\hline Prairie provinces & $32(12.3)$ \\
\hline British Columbia & $38(14.6)$ \\
\hline Maritime provinces & 13 (4.9) \\
\hline Impaired immune statust & 12 (4.6) \\
\hline \multicolumn{2}{|l|}{ Herpes zoster } \\
\hline \multicolumn{2}{|l|}{ Primary dermatome affected $\ddagger$} \\
\hline Trigeminal & $13 \quad(5.2)$ \\
\hline Cervical & $51(20.3)$ \\
\hline Thoracic & $124(49.4)$ \\
\hline Lumbar & $48(19.1)$ \\
\hline Sacral & $15 \quad(6.0)$ \\
\hline \multicolumn{2}{|l|}{ No. of lesions§ } \\
\hline $1-10$ & $96(38.4)$ \\
\hline $11-20$ & $52(20.8)$ \\
\hline $21-50$ & $58(23.2)$ \\
\hline$>50$ & $44(17.6)$ \\
\hline Worst pain score, mean (SD) & $5.7(3.0)$ \\
\hline Prodromal pain & $186(74.1)$ \\
\hline $\begin{array}{l}\text { Duration of prodromal pain, } d, \\
\text { mean }(S D)^{* *}\end{array}$ & $4.6(4.3)$ \\
\hline $\begin{array}{l}\text { Worst prodromal pain score, } \\
\text { mean }(\mathrm{SD})^{* *}\end{array}$ & $5.9(2.7)$ \\
\hline \multicolumn{2}{|c|}{ Initial treatment of herpes zoster } \\
\hline Antiviral medicationt† & $232(88.9)$ \\
\hline NSAID/analgesic & $28(10.7)$ \\
\hline Opiate/narcotic & $59(22.6)$ \\
\hline Antidepressant & $38(14.6)$ \\
\hline Anticonvulsant & $18 \quad(6.9)$ \\
\hline Anxiolytic/hypnotic & $2(0.8)$ \\
\hline Corticosteroid & $4 \quad(1.5)$ \\
\hline Ophthalmic agent & $7 \quad(2.7)$ \\
\hline Topical agent & $37(14.2)$ \\
\hline
\end{tabular}

Note: NSAID = nonsteroidal anti-inflammatory drug, SD = standard deviation. *Unless stated otherwise.

tReasons for impaired immune status were high-dose corticosteroids $(n=2)$, cancer $(n=4)$, HIV infection $(n=1)$, drug treatment for cancer $(n=3)$, immunosuppressive therapy $(n=6)$ and organ transplant therapy $(n=1)$.

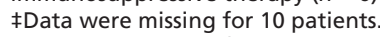

§Data were missing for 11 patients.

**Calculated among the 186 participants who reported prodromal pain

††Antiviral agents received were acyclovir $(n=13)$, valacyclovir $(n=103)$ and famciclovir $(n=116)$ using the Pearson correlation coefficient. We verified the influence of age on the change in quality of life by including an interaction term between age and time.

For categorical variables (percentage of participants reporting problems in EQ-5D health domains, and percentage of participants reporting a score of five or higher for the interference of pain with their activities of daily living), we used the same piece-wise linear regression models as for continuous variables, but with log-binomial regression. These models were used to describe the mean EQ-5D scores or proportions of participants reporting problems at different points of follow-up for the total study cohort. We replicated these models among participants who reported clinically significant pain at each follow-up point.

We used Kaplan-Meier curves to estimate the median duration of pain and the duration of interference with activities of daily living because of pain. The duration of pain was calculated from the onset of the rash until the cessation of pain (defined as the first of two consecutive questionnaires without clinically significant pain, as defined by Coplan and colleagues ${ }^{8}$. We used a similar method to estimate the duration of interference with activities of daily living because of pain.

\section{Results}

Of the 261 eligible participants, 215 (82.4\%) completed all 10 questionnaires. Participants' characteristics are presented in Table 1. Most (232 [88.9\%]) were initially treated with antiviral medication, and $12(4.6 \%)$ were immunocompromised. At recruitment, $218(83.5 \%)$ reported moderate to severe pain (score of $\geq 3$ out of 10 ), and only 13 (5.0\%) reported having no pain.

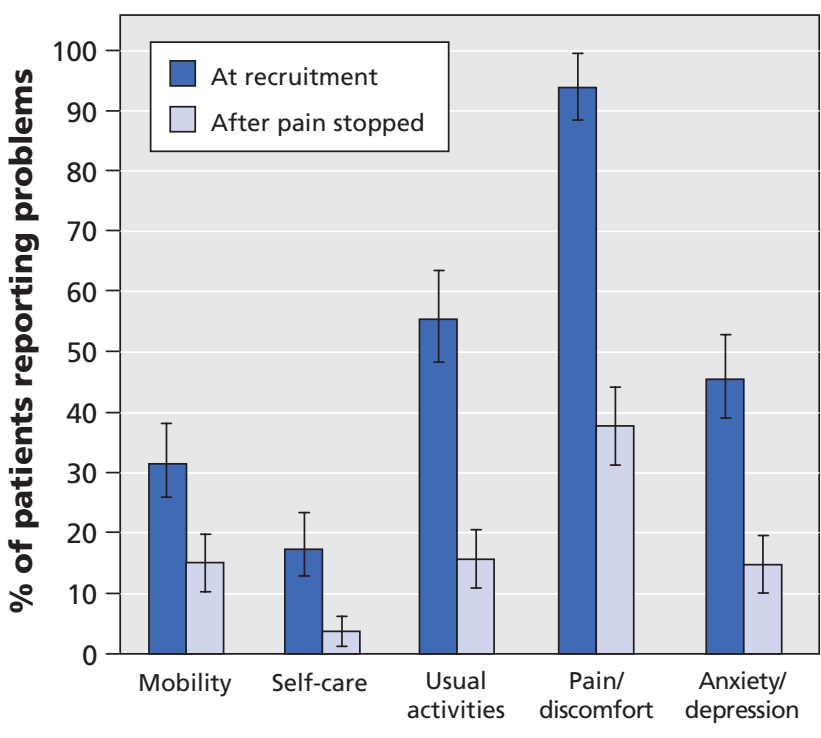

Figure 1: Impact of herpes zoster on health-related quality of life. Shown are the percentages of participants $(n=261)$ who reported problems in the EuroQol EQ-5D domains at the time of recruitment ( $<14$ days after rash onset) and after the pain stopped. Median duration of pain was 32.5 days. Error bars = 95\% confidence intervals. 
The proportion of participants who reported that herpes zoster was having a considerable impact on their quality of life was higher at recruitment than after the pain stopped, particularly in terms of pain and discomfort $(93.8 \%$ at recruitment, $37.8 \%$ after pain cessation) and usual activities (55.4\% at recruitment, $15.7 \%$ after pain cessation) (Figure 1). Acute pain from herpes zoster greatly interfered with the activities of daily living. More than half of the participants reported interference scores of five or greater at recruitment in the areas of sleep (63.9\%), enjoyment of life (58.2\%) and general activities (52.6\%) (Appendix 1, available at www.cmaj.ca/cgi/content/full/cmaj.091711/DC1). The impact of acute herpes zoster on quality of life was similar over all age groups, with an EQ-5D utility score of 0.59 at recruitment (Table 2).

The median duration of interference with activities of daily living because of pain varied between 27.0 days (relations with others) and 29.8 days (sleep). This is consistent with the median duration of pain from herpes zoster (32.5 days) (Appendix 2, available at www.cmaj.ca/cgi/content/full/cmaj $.091711 / \mathrm{DC} 1)$. Quality of life was highly correlated with severity of pain throughout the follow-up period (Pearson correlation coefficient $0.68, p<0.001$ ). The mean EQ-5D score increased significantly during the first 30 days (by 4.2 points per week; $p<0.001$ ), continued to increase significantly, but at a slower rate, between 30 and 90 days (by 1.1 points per week; $p<0.001)$ and remained stable after 90 days (change of 0.2 points per week; $p=0.19$ ) (Figure 2). For participants who reported clinically significant pain at each fol- low-up point, the mean EQ-5D score remained constant at 0.67 as long as pain persisted (Table 2).

A total of 63 participants (24.1\%) had postherpetic neuralgia (Table 2). None of these patients had pain that began after 90 days. Older patients were more likely to have postherpetic neuralgia $(32.9 \%$ of those aged $>70$ years v. $16.8 \%$ of those aged 50-60 years). At the onset of the postherpetic neuralgia (i.e., 90 days after rash onset), the mean quality-of-life utility score was 0.67 . A high proportion of these participants reported pain or discomfort, symptoms of anxiety or depression, and problems with mobility and self-care throughout the postherpetic period (Figure 3). Postherpetic neuralgia interfered mostly with enjoyment of life, mood and sleep (Appendix 1). Because the older participants were more likely than those who were younger to have postherpetic neuralgia, they also reported greater interference with activities of daily living because of pain during the postherpetic neuralgia period (Appendix 1).

\section{Interpretation}

Acute herpes zoster significantly affected quality of life and functional status. Sleep, enjoyment of life, general activities, mood, normal work, and the quality-of-life domains of pain or discomfort and usual activities were particularly affected. These findings were consistent across all age groups. Postherpetic neuralgia developed in $24 \%$ of the participants, with older patients being at greatest risk. Changes in quality of life over time closely correlated with the severity of pain and persisted as long as clinically significant pain continued. Partici-

Table 2: Pain scores and quality-of-life utility scores among participants with herpes zoster who reported clinically significant pain* at different follow-up points after onset of rash

Time since onset of rash

\begin{tabular}{|c|c|c|c|c|}
\hline \multirow{2}{*}{ Variable; age groupt } & \\
\hline & 0 days & 30 days & 90 days $\neq$ & 180 days \\
\hline $50-60 \mathrm{yr}$ & $101(100)$ & $50(49.5)$ & $17(16.8)$ & $6(5.9)$ \\
\hline $61-70 \mathrm{yr}$ & $78(100)$ & $49(62.8)$ & $19(24.4)$ & $11(14.1)$ \\
\hline$>70 \mathrm{yr}$ & $82(100)$ & $51(62.2)$ & $27(32.9)$ & $17(20.7)$ \\
\hline Total & $261(100)$ & $150(57.5)$ & $63(24.1)$ & $34(13.0)$ \\
\hline $50-60 \mathrm{yr}$ & $5.9(5.4-6.6)$ & $3.1(2.5-3.7)$ & $3.1(2.6-3.6)$ & $3.2(2.0-4.4)$ \\
\hline $61-70 \mathrm{yr}$ & $7.4(6.7-8.1)$ & $4.1(3.5-4.7)$ & $4.0(3.6-4.5)$ & $3.9(2.9-4.9)$ \\
\hline$>70 \mathrm{yr}$ & $5.7(5.0-6.4)$ & $4.2(3.6-4.7)$ & $4.2(3.8-4.6)$ & $4.2(3.3-5.0)$ \\
\hline Total & $6.3(5.9-6.7)$ & $3.8(3.4-4.1)$ & $3.8(3.5-4.1)$ & $3.9(3.3-4.5)$ \\
\hline \multicolumn{5}{|c|}{ Mean EQ-5D score $(95 \% \mathrm{CI}) \S$} \\
\hline Total & $0.59(0.55-0.64)$ & $0.67(0.64-0.71)$ & $0.67(0.64-0.70)$ & $0.67(0.61-0.73)$ \\
\hline
\end{tabular}

Note: $\mathrm{Cl}=$ confidence interval, EQ-5D = EuroQol quality-of-life assessment tool.

*Clinically significant pain $=$ any pain score during the period from rash onset to 30 days, and a pain score of $\geq 3$ after 30 days. ${ }^{8}$

tThe age distribution of the participants was 39\% $(n=101)$ aged $50-60 \mathrm{yr}, 30 \%(n=78)$ aged $61-70 \mathrm{yr}$ and $31 \%(n=82)$ aged $>70 \mathrm{yr}$.

¥Participants who were still reporting clinically significant pain at 90 days were considered to have postherpetic neuralgia. ${ }^{8}$

$\S$ The mean pain score and EQ-5D scores were calculated for participants still reporting clinically significant pain at the different follow-up points. For example, a mean pain score of 3.8 at 90 days was calculated for the 63 participants still reporting pain at that time. 
pants with postherpetic neuralgia most frequently reported problems with anxiety or depression, enjoyment of life, mood and sleep.

Although the rash and pain associated with herpes zoster usually disappear within one month, our findings support the evidence that acute herpes zoster has a major impact on health-related quality of life and functional status. ${ }^{16,17,30}$ Significant impairment across different age groups indicated that younger patients were as likely as older ones to be affected by acute herpes zoster. At recruitment, the quality-of-life EQ-5D score was 0.59 , as compared with 0.78 for the Canadian ageand sex-adjusted population. ${ }^{31}$ The difference between the two scores greatly exceeds a proposed cut-off of 0.07 for minimally important differences. ${ }^{32}$

Our findings confirm previous observations from crosssectional surveys, which suggest that postherpetic neuralgia interferes mostly with enjoyment of life, mood, sleep and general activities. ${ }^{19}$ The $24 \%$ of participants who had postherpetic neuralgia in our study is higher than the proportion reported in the Shingles Prevention Study (12\%). ${ }^{13}$ This difference is most likely because we included patients seeking care, whereas the other study included all actively sought patients, some of whom might not have otherwise sought care. However, our proportion of patients who had postherpetic neuralgia is similar to the proportion reported in a study in England (27\%), which included a population seeking care for herpes zoster. ${ }^{14}$ Because older participants were more likely than younger ones to have postherpetic neuralgia and consequently experienced greater impairment in their quality of life, preventive measures may be most beneficial for these age groups. Clinicians should be aware that patients who continue to experience herpetic pain are likely to experience interference with activities of daily living, anxiety or depression, and insomnia and will need careful management of these conditions.

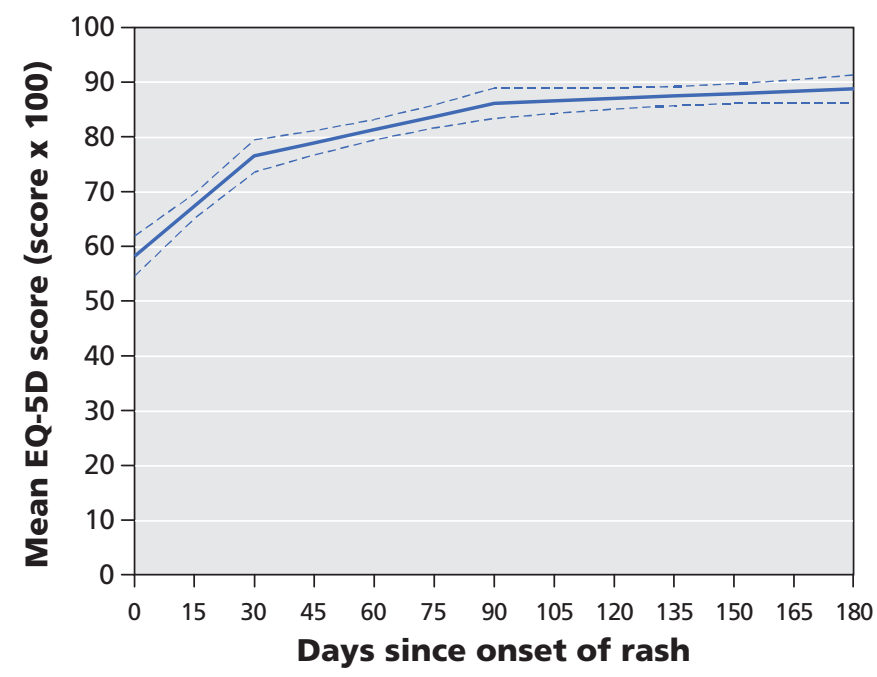

Figure 2: Change in health-related quality of life over time, as indicated by change in mean EuroQol EQ-5D scores, among patients with herpes zoster. Dotted lines represent 95\% confidence intervals.

\section{Limitations}

To make large-scale recruitment feasible and to reproduce real-life clinic conditions, we imposed minimal additional workload on recruiting physicians beyond that needed to treat their patients. For this reason, the main limitation of our study is that participation was not necessarily offered to all eligible patients, and the proportion of eligible patients who declined the invitation was not documented. However, our participants compared favourably with other study populations of patients with herpes zoster. ${ }^{10,33-35}$ Our results should thus be generalizable to patients seeking care for herpes zoster during the acute phase. Our data are also likely to present information bias such as learning effects because of repeated testing with the same instrument over time. Nonetheless, the close link between the change in severity of pain and quality of life over time provides some reassurance regarding the validity of our data. Finally, as in any prospective study assessing the influence of a disease on quality of life, a part of the change over time may have been attributable to response shifts. ${ }^{36,37}$

Although $90 \%$ of the study cohort was initially given antiviral treatment, herpes zoster and postherpetic neuralgia severely affected all health domains and activities of daily living. In addition, a recent Cochrane meta-analysis did not provide evidence to support the use of antivirals to prevent postherpetic neuralgia, ${ }^{38}$ although evidence is lacking for some specific antivirals.

Our study has several strengths. First, unlike studies that recruited patients with herpes zoster or postherpetic neuralgia at different intervals from rash onset and consequently were more subject to selection bias, ${ }^{18-20}$ we recruited patients at the time of diagnosis of herpes zoster and followed them long enough to

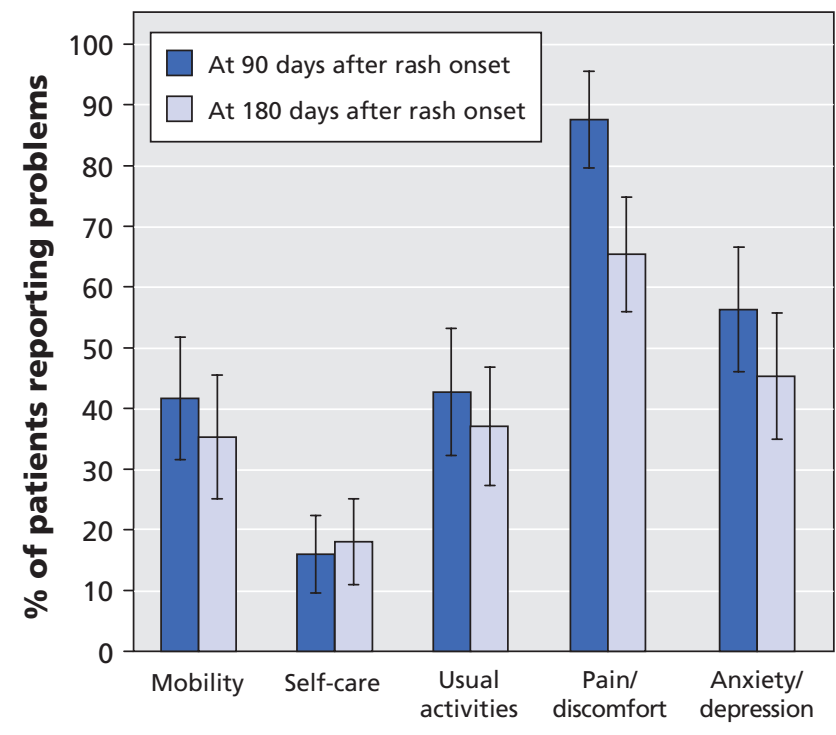

Figure 3: Impact of postherpetic neuralgia on health-related quality of life. Shown are the percentages of participants with postherpetic neuralgia $(n=63)$ who reported problems in the EuroQol EQ-5D domains at 90 days after rash onset (the start of the postherpetic neuralgia) and at 180 days after rash onset. Error bars $=95 \%$ confidence intervals. 
allow the development of postherpetic neuralgia. Second, we described the change in specific health domains over time for participants with postherpetic neuralgia, unlike previous crosssectional descriptions. ${ }^{18-20}$ Finally, we tested $41 \%$ of the eligible patients for the presence of varicella-zoster virus DNA and confirmed the diagnosis in $95 \%$ of those tested.

\section{Conclusion}

These results provide new information on the burden of herpes zoster and postherpetic neuralgia from the patient's perspective. These data reinforce the need for effective preventive strategies, such as vaccination, and additional early intervention to reduce the burden of herpes zoster and postherpetic neuralgia.

\section{This article has been peer reviewed.}

Competing interests: Marc Brisson was an employee of Merck Frosst Canada Ltd. from 2003 to 2006; within the past five years, he has consulted for Merck Frosst and has received reimbursement for travel expenses from GlaxoSmithKline. Kenneth Schmader has received grant support from Merck and Wyeth and has consulted for Merck and GlaxoSmithKline. Myron Levin has consulted for Merck Frosst; he has received research funds from Merck and is on their speakers bureau. Robert Johnson has consulted and has received honoraria for public speaking from Merck Frosst, Merck (US), Sanofi Pasteur Merck, Astellas, Novartis and GlaxoSmithKline. Michael Oxman has consulted for Merck Frosst and is national chairman of the Shingles Prevention Study (VA Cooperative Study no. 403) and its substudies, which have been supported in part by grants from Merck to the VA Cooperative Studies Program, to the VA San Diego Medical Research Foundation and to the VA Connecticut Research and Education Foundation. James Mansi was an employee of Merck Frosst Canada Ltd. No competing interests declared by Mélanie Drolet, David Patrick and Caty Blanchette. Merck Frosst is the developer and distributor of the shingles vaccine.

Contributors: Marc Brisson, Kenneth Schmader, Myron Levin, Michael Oxman, Robert Johnson, David Patrick and James Mansi contributed to the conception and design of the study. Caty Blanchette and Mélanie Drolet conducted the analysis, and all of the authors assisted in the interpretation of the results. Mélanie Drolet, with the help of Marc Brisson, drafted the manuscript. All of the authors critically reviewed the manuscript for important intellectual content and approved the final version submitted for publication.

Acknowledgement: The authors thank JSS Medical Research Inc., for gathering the study data, and the physicians who recruited the patients for the study.

Funding: This study was funded by Merck Frosst Canada Ltd. and was conducted under a collaborative research agreement between Merck Frosst Canada Ltd. and the study's scientific steering committee, which comprised Marc Brisson, Myron Levin, Kenneth Schmader, Michael Oxman, Robert Johnson, David Patrick and James Mansi. This research was undertaken, in part, thanks to funding from the Canada Research Chairs. The scientific steering committee was responsible for the development of the study protocol and for the direction of the study. The study data set is housed in the Centre hospitalier affilié universitaire de Québec - Hôpital du Saint-Sacrement, Québec, Que., where the data analysis was conducted under the direction of the scientific steering committee. Merck Frosst Canada Ltd. does not have any ownership rights to the findings and results of the study. The scientific steering committee has absolute discretion and the final decision over the contents and authorship of all publications or presentations.

\section{REFERENCES}

1. Gnann JW Jr, Whitley RJ. Clinical practice. Herpes zoster. N Engl J Med 2002; 347:340-6.

2. Head H, Campbell AW, Kennedy PG. The pathology of herpes zoster and its bearing on sensory localisation. Rev Med Virol 1997;7:131-43.

3. Hope-Simpson RE. The nature of herpes zoster: a long-term study and a new hypothesis. Proc R Soc Med 1965;58:9-20.

4. Weller TH. Varicella and herpes zoster. Changing concepts of the natural history, control, and importance of a not-so-benign virus. N Engl J Med 1983;309:1434-40.

5. Brisson M, Edmunds WJ, Law B, et al. Epidemiology of varicella zoster virus infection in Canada and the United Kingdom. Epidemiol Infect 2001;127:305-14.

6. Edmunds WJ, Brisson M, Rose JD. The epidemiology of herpes zoster and potentia cost-effectiveness of vaccination in England and Wales. Vaccine 2001;19:3076-90.

7. Insinga RP, Itzler RF, Pellissier JM, et al. The incidence of herpes zoster in a
United States administrative database. J Gen Intern Med 2005;20:748-53.

8. Coplan PM, Schmader K, Nikas A, et al. Development of a measure of the burden of pain due to herpes zoster and postherpetic neuralgia for prevention trials: adaptation of the Brief Pain Inventory. J Pain 2004:5:344-56.

9. Oxman MN. Clinical manifestation of herpes zoster. In: Arvin AM, Gerson AA editors. Varicella zoster virus: virology and clinical management. Cambridge (UK): Cambridge University press; 2000. p. 246-75.

10. Opstelten W, Zuithoff NP, van Essen GA, et al. Predicting postherpetic neuralgia in elderly primary care patients with herpes zoster: prospective prognostic study. Pain 2007;132(Suppl 1):S52-9.

11. Schmader KE. Epidemiology and impact on quality of life of postherpetic neuralgia and painful diabetic neuropathy. Clin J Pain 2002;18:350-4.

12. Dworkin R, Schmader K. The epidemiology and natural history of herpes zoster and postherpetic neuralgia. In: Herpes zoster and postherpetic neuralgia. 2nd ed. Amsterdam (Netherlands): Elsevier; 2001. p. 39-65.

13. Oxman MN, Levin MJ, Johnson GR, et al. A vaccine to prevent herpes zoster and postherpetic neuralgia in older adults. $N$ Engl J Med 2005;352:2271-84.

14. Scott FT, Leedham-Green ME, Barrett-Muir WT, et al. A study of shingles and the development of postherpetic neuralgia in East London. J Med Virol 2003;70:S24-30.

15. Yawn BP, Saddier P, Wollan PC, et al. A population-based study of the incidence and complication rates of herpes zoster before zoster vaccine introduction. Mayo Clin Proc 2007;82:1341-9.

16. Katz J, Cooper EM, Walther RR, et al. Acute pain in herpes zoster and its impact on health-related quality of life. Clin Infect Dis 2004;39:342-8.

17. Schmader KE, Sloane R, Pieper C, et al. The impact of acute herpes zoster pain and discomfort on functional status and quality of life in older adults. Clin J Pain 2007;23:490-6.

18. van Seventer R, Sadosky A, Lucero M, et al. A cross-sectional survey of health state impairment and treatment patterns in patients with postherpetic neuralgia. Age Ageing 2006;35:132-7.

19. Oster G, Harding G, Dukes E, et al. Pain, medication use, and health-related quality of life in older persons with postherpetic neuralgia: results from a populationbased survey. J Pain 2005;6:356-63.

20. Chidiac C, Bruxelle J, Daures JP, et al. Characteristics of patients with herpes zoster on presentation to practitioners in France. Clin Infect Dis 2001;33:62-9.

21. Galer BS, Gianas A, Jensen MP. Painful diabetic polyneuropathy: epidemiology, pain description, and quality of life. Diabetes Res Clin Pract 2000;47:123-8.

22. Brazier J, Jones N, Kind P. Testing the validity of the EuroQol and comparing it with the SF-36 health survey questionnaire. Qual Life Res 1993;2:169-80.

23. Dolan P. Modeling valuations for EuroQol health states. Med Care 1997;35:1095-108.

24. Huang IC, Willke RJ, Atkinson MJ, et al. US and UK versions of the EQ-5D preference weights: Does choice of preference weights make a difference? Qual Life Res 2007;16:1065-72.

25. Agency for Healthcare Research and Quality. US valuation of the EuroQol EQ-5D health states. Rockville (MD): The Agency; 2005. Available: www.ahrq.gov /rice/EQ5Dproj.htm (accessed 2005 Dec. 10).

26. Fairclough D. Design and analysis of quality of life studies in clinical trials. Boca Raton (FL): Chapman And Hall/CRC Press; 2002.

27. Dworkin RH, Gnann JW Jr, Oaklander AL, et al. Diagnosis and assessment of pain associated with herpes zoster and postherpetic neuralgia. J Pain 2008;9(Suppl 1): S37-44.

28. Desmond RA, Weiss HL, Arani RB, et al. Clinical applications for change-point analysis of herpes zoster pain. J Pain Symptom Manage 2002;23:510-6.

29. Drolet M, Brisson M, Levin MJ, et al. A prospective study of the herpes zoster severity of illness. Clin J Pain 2010;26:656-66.

30. Lydick E, Epstein RS, Himmelberger D, et al. Herpes zoster and quality of life: a self-limited disease with severe impact. Neurology 1995;45(Suppl 8):S52-3.

31. Johnson JA, Pickard AS. Comparison of the EQ-5D and SF-12 health surveys in a general population survey in Alberta, Canada. Med Care 2000;38:115-21.

32. Walters SJ, Brazier JE. Comparison of the minimally important difference for two health state utility measures: EQ-5D and SF-6D. Qual Life Res 2005;14:1523-32.

33. Tyring SK, Beutner KR, Tucker BA, et al. Antiviral therapy for herpes zoster: randomized, controlled clinical trial of valacyclovir and famciclovir therapy in immunocompetent patients 50 years and older. Arch Fam Med 2000;9:863-9.

34. Beutner KR, Friedman DJ, Forszpaniak C, et al. Valaciclovir compared with acyclovir for improved therapy for herpes zoster in immunocompetent adults. Antimicrob Agents Chemother 1995;39:1546-53.

35. Whitley RJ, Weiss H, Gnann JW Jr, et al. Acyclovir with and without prednisone for the treatment of herpes zoster. A randomized, placebo-controlled trial. The National Institute of Allergy and Infectious Diseases Collaborative Antiviral Study Group. Ann Intern Med 1996;125:376-83.

36. Sprangers MA, Schwartz CE. Integrating response shift into health-related quality of life research: a theoretical model. Soc Sci Med 1999;48:1507-15.

37. Schwartz CE, Sprangers MA. Methodological approaches for assessing response shift in longitudinal health-related quality-of-life research. Soc Sci Med 1999;48:1531-48.

38. Li Q, Chen N, Yang J, et al. Antiviral treatment for preventing postherpetic neuralgia [review]. Cochrane Database Syst Rev 2009;(2):CD006866.

Correspondence to: Dr. Marc Brisson, Unité de recherche en santé des populations, Centre hospitalier affilié universitaire de Québec, Hôpital Saint-Sacrement, 1050 Chemin Sainte-Foy, Québec QC G1S 4L8; marc.brisson@uresp.ulaval.ca 